\title{
Densidade de plantas em híbridos de milho semeados no final do inverno em ambientes irrigados e de sequeiro
}

\author{
Michael da Silva Serpa(1), Paulo Regis Ferreira da Silva(1), Luis Sangoi(2), \\ Vladirene Macedo Vieira( ${ }^{(3)}$ e Darlan Rodrigo Marchesi ${ }^{(4)}$
}

\begin{abstract}
(1)Universidade Federal do Rio Grande do Sul, Departamento de Plantas de Lavoura, Avenida Bento Gonçalves, no 7.712, Caixa Postal 15100, CEP 91540-000 Porto Alegre, RS. E-mail: micaserpa@yahoo.com.br, paulo.silva@ufrgs.br (2)Universidade do Estado de Santa Catarina, Departamento de Agronomia, Avenida Luiz de Camões, № 2.090, CEP 88520-000 Lages, SC. E-mail: a2ls@cav.udesc (3)Embrapa Trigo, Rodovia BR 285, Km 294, Caixa Posta 451, CEP 99001-970 Passo Fundo, RS. E-mail: vladirene@gmail.com ${ }^{(4)}$ Empresa de Pesquisa Agropecuária e Extensão Rural de Santa Catarina, Rodovia Admar Gonzaga, no 1.347, Caixa Postal 502, CEP 88034-901 Florianópolis, SC. E-mail: darlanmarchesi@hotmail.com
\end{abstract}

Resumo - O objetivo deste trabalho foi avaliar a densidade de plantas de híbridos de milho semeados antecipadamente (agosto e setembro), durante o final do inverno no Sul do Brasil, em ambientes irrigados e de sequeiro. Implantaram-se dois experimentos em 2008/2009 (um irrigado durante todo o ciclo e outro apenas de $\mathrm{V}_{15}$ a $R_{2}$ ) e três em 2009/2010 (além dos níveis anteriores, acrescentou-se um sob condições naturais de precipitação). Em cada experimento, avaliaram-se quatro densidades (5, 7,9 e 11 plantas por metro quadrado), quatro híbridos em 2008/2009 e três híbridos em 2009/2010. Em 2008/2009, ocorreram períodos de deficiência hídrica que totalizaram $84 \mathrm{~mm}$ nos estádios $\mathrm{V}_{3}, \mathrm{~V}_{11}$ a $\mathrm{V}_{15}$, e $\mathrm{R}_{4}$. Em 2009/2010, ocorreu deficiência hídrica apenas no estádio $\mathrm{R}_{5}$. Nos dois anos, as máximas produtividades de grãos ultrapassaram $13 \mathrm{Mg} \mathrm{ha}^{-1} \mathrm{e}$ foram obtidas com densidades superiores a nove plantas por metro quadrado, independentemente da disponibilidade hídrica e do híbrido. A utilização de altas densidades é uma estratégia eficiente para otimizar a produtividade de grãos do milho semeado no final do inverno nas regiões mais quentes do Sul do Brasil, desde que não haja deficiência hídrica entre $V_{15}$ e $R_{2}$.

Termos para indexação: Zea mays, arranjo de plantas, componentes do rendimento, disponibilidade hídrica.

\section{Plant density of maize hybrids sowed during late winter in irrigated and rainfed environments}

\begin{abstract}
The objective of this work was to determine plant density of maize hybrids sowed early (August and September), at the end of winter in the South of Brazil, in irrigated and rainfed environments. Two experiments were set in 2008/2009 (one irrigated throughout the whole cycle and another only from $V_{15}$ to $R_{2}$ ) and three in 2009/2010 (in addition to the previous levels, an experiment under natural rainfall was included). In each experiment, four densities (5, 7, 9, and 11 plants per square meter), four hybrids in 2008/2009, and three hybrids in 2009/2010 were evaluated. In 2008/2009, there were periods of water deficit that added $84 \mathrm{~mm}$ in the stages $\mathrm{V}_{3}, \mathrm{~V}_{11}$ to $\mathrm{V}_{15}$, and $\mathrm{R}_{4}$. In 2009/2010, water deficiency occurred only in the $\mathrm{R}_{5}$ stage. In both years, maximum grain yield exceeded $13 \mathrm{Mg} \mathrm{ha}^{-1}$ and was obtained with densities higher than nine plants per square meter, regardless of water availability and hybrid. The use of high densities is an efficient strategy to optimize maize grain yield sowed during late winter in the warmer regions of the South of Brazil, as long as there is no water deficit between $V_{15}$ and $R_{2}$.
\end{abstract}

Index terms: Zea mays, plant arrangement, yield components, water availability.

\section{Introdução}

Para obter elevadas produtividades de grãos de milho (Zea mays L.), é necessário adequar as práticas de manejo aos recursos disponíveis no ambiente, para proporcionar as melhores condições ao desenvolvimento das plantas. Entre as estratégias de manejo que podem ser utilizadas para aumentar a produtividade de milho, a adequação da época de semeadura e da densidade de plantas é de fundamental importância.

As condições climáticas das regiões mais quentes do Sul do Brasil, caracterizadas por baixas altitudes e temperaturas elevadas no verão, permitem o cultivo do milho em ampla faixa de época de semeadura. No entanto, para potencializar a produtividade de grãos, a escolha da época de semeadura deve receber maior atenção. Quando não há limitação de disponibilidade hídrica, a época preferencial para a semeadura do milho é aquela que faz coincidir o estádio em que as plantas estão com maior área foliar (espigamento) com o período do ano com maior disponibilidade de radiação solar (meados de dezembro a meados de janeiro) e com condições de temperatura favoráveis (em torno de 
$25-30^{\circ} \mathrm{C}$ ). Isso ocorre quando a semeadura é realizada em outubro (Sangoi et al., 2010b). Entretanto, nessas regiões mais quentes, há maior probabilidade de ocorrência de deficiência hídrica no período mais crítico da cultura, entre os estádios $\mathrm{V}_{15}$ e $\mathrm{R}_{2}$ da escala de Ritchie et al. (1993), quando a semeadura do milho é realizada em outubro (Matzenauer et al., 2002). Portanto, na ausência de irrigação, tem-se recomendado a antecipação da época de semeadura para o início de agosto até meados de setembro (final do inverno), como estratégia de escape da ocorrência da deficiência hídrica no período mais crítico da cultura. A antecipação da semeadura para o final do inverno também viabiliza o cultivo de uma segunda cultura estival em sucessão, como a soja ou o feijão. Assim, obtém-se maior eficiência de uso da terra, o que contribui para o aumento da rentabilidade dos produtores.

Além da adequação da época de semeadura, a escolha da densidade de plantas tem grande influência na produtividade de grãos de milho. Isso porque, diferentemente de outras espécies da família das poáceas, o milho apresenta baixa capacidade de compensar espaços vazios, por raramente perfilhar e por apresentar limitada capacidade de expansão foliar e baixa prolificidade (Sangoi et al., 2010a).

A determinação da densidade de plantas em milho depende de vários fatores, como época de semeadura, cultivar, fertilidade e adubação do solo e nível de disponibilidade hídrica. Este último é o que mais limita a produtividade de grãos (Matzenauer et al., 2002). O incremento da densidade de plantas aumenta a competição intraespecífica pelos recursos hídricos disponíveis, pois propicia aumento do índice de área foliar (IAF) e, consequentemente, da evapotranspiração da cultura. Apesar do aumento da competição intraespecífica decorrente da elevação da densidade de plantas, nas regiões mais quentes do Sul do Brasil, podese aumentar a densidade de plantas nas semeaduras antecipadas para o final do inverno, uma vez que há maior probabilidade de escapar da deficiência hídrica no período mais crítico da cultura. Além disso, nas semeaduras realizadas antes de meados de setembro, as temperaturas do ar e do solo e a disponibilidade de radiação solar são menores, o que resulta em plantas mais baixas, com menor área foliar. Em função disso, podem ser requeridas maiores densidades de plantas para aumentar o IAF, a interceptação da radiação solar incidente e a produtividade de grãos, para compensar o menor desenvolvimento vegetativo das plantas (Piana et al., 2008).

Outro fator importante na escolha da densidade de plantas é o híbrido de milho utilizado. A densidade de plantas recomendada para o milho foi alterada ao longo do tempo, à medida que modificações de ordem genética, fisiológica, bioquímica e anatômica foram incorporadas nas plantas pelos programas de melhoramento, concomitantemente com as mudanças no manejo da cultura. Os híbridos lançados a partir da década de 1990 foram selecionados sob altas densidades de plantas, tendo-se tornado, também, mais tolerantes aos estresses ocasionados por deficiência hídrica ou nutricional (Duvick, 1997). Campos et al. (2004) e Borras et al. (2007) evidenciaram mudanças na arquitetura do sistema radicular dos híbridos recentes, que são capazes de absorver água de camadas mais profundas do solo e, assim, apresentar maior tolerância à deficiência hídrica. Portanto, a utilização de híbridos modernos associada à antecipação da época de semeadura pode permitir o incremento da densidade de plantas, o que aumenta a produtividade e a estabilidade do rendimento.

Vários trabalhos sobre densidade de plantas em milho foram desenvolvidos no Brasil, com uso de adubação nitrogenada (Von Pinho et al., 2008), espaçamento entrelinhas (Penariol et al., 2003), híbridos de arquitetura e ciclos contrastantes (Piana et al., 2008), e diferentes níveis de manejo (Peixoto et al., 1997). Entretanto, há poucas pesquisas sobre a interação entre a densidade de plantas e o nível de disponibilidade hídrica em semeaduras antecipadas para o final de inverno, em regiões quentes do Sul do país.

O objetivo deste trabalho foi avaliar a densidade de plantas de híbridos de milho semeados antecipadamente (agosto e setembro), durante o final do inverno no Sul do Brasil, em ambientes irrigados e de sequeiro.

\section{Material e Métodos}

Cinco experimentos foram conduzidos em campo, no Município de Eldorado do Sul, região ecoclimática da Depressão Central do Estado do Rio Grande do Sul ( $30^{\circ} 05^{\prime} \mathrm{S}$ e $51^{\circ} 39^{\prime} \mathrm{W}$, a $42 \mathrm{~m}$ de altitude). O solo da área experimental foi classificado como Argissolo Vermelho distrófico típico (Streck et al., 2008). 
No primeiro ano agrícola (2008/2009), foram realizados dois experimentos: um com irrigação complementar durante todo o ciclo da cultura e outro com irrigação apenas durante o período mais crítico da cultura do milho, do estádio $\mathrm{V}_{15}$ a $\mathrm{R}_{2}$, conforme escala de Ritchie et al. (1993). Em cada experimento, os tratamentos consistiram de quatro densidades de plantas $(5,7,9$ e 11 plantas por metro quadrado) e de quatro híbridos simples de ciclo precoce (AS 1565, 30R50, 2B707 e NB 7502). Utilizou-se o delineamento experimental de blocos ao acaso, em arranjo fatorial $4 \times 4$, com três repetições.

No segundo ano agrícola (2009/2010), além dos dois níveis de disponibilidade hídrica utilizados em 2008/2009, foi acrescentado um nível sob condições naturais de precipitação pluvial, o que totalizou três experimentos. Em cada experimento, foram testadas quatro densidades de plantas $(5,7,9$ e 11 plantas por metro quadrado) e três híbridos simples de milho de ciclo precoce (30R50, 2A550 e Status). Utilizouse o delineamento experimental de blocos ao acaso em arranjo fatorial $3 \times 4$, com quatro repetições. Os híbridos utilizados foram escolhidos por serem simples, modernos, de ciclo curto e por apresentarem alto potencial de produtividade.

No primeiro ano, o milho foi semeado em 27/8/2008. Realizou-se o tratamento de sementes com o inseticida thiodicarbe, na dose de ingrediente ativo por 7,0 $\mathrm{g} \mathrm{kg}^{-1}$ de sementes. No segundo ano, o milho foi semeado em 16/9/2009. As sementes foram tratadas com o inseticida carbofuran, na dose de ingrediente ativo por $20 \mathrm{~g} \mathrm{~kg}^{-1}$ de sementes. Nos dois anos, o milho foi semeado em sistema plantio direto, com auxílio de semeadora manual (saraquá), em sucessão ao nabo-forrageiro. A adubação na semeadura foi baseada na análise de solo e seguiu as indicações técnicas para obtenção de produtividade de grãos superiores a $12 \mathrm{Mg} \mathrm{ha}^{-1}$. Aplicou-se 20, 120 e $120 \mathrm{~kg} \mathrm{ha}^{-1} \mathrm{de} \mathrm{N}, \mathrm{P}_{2} \mathrm{O}_{5}$ e $\mathrm{K}_{2} \mathrm{O}$, respectivamente, na forma de adubo químico, pela mistura de $400 \mathrm{~kg} \mathrm{ha}^{-1}$ da fórmula 5-30-15 mais $100 \mathrm{~kg} \mathrm{ha}^{-1}$ de cloreto de potássio $\left(60 \%\right.$ de $\left.\mathrm{K}_{2} \mathrm{O}\right)$. A adubação foi aplicada com semeadora adubadora em linhas, regulada para depositar apenas o adubo no sulco de semeadura. A emergência das plântulas ocorreu aos 18 e aos 11 dias após a semeadura, no primeiro e no segundo ano, respectivamente. $\mathrm{O}$ ajuste das densidades de plantas foi realizado nos estádios $V_{2}$ a $V_{3}$, em torno de 14 dias após a emergência, pelo desbaste manual.
No primeiro ano, a adubação nitrogenada de cobertura foi de $230 \mathrm{~kg} \mathrm{ha}^{-1}$ de $\mathrm{N}$, divididos em três parcelas: $80 \mathrm{~kg} \mathrm{ha}^{-1}$ aplicados no estádio $\mathrm{V}_{5}-\mathrm{V}_{6}, 100 \mathrm{~kg} \mathrm{ha}^{-1}$ no estádio $\mathrm{V}_{9}-\mathrm{V}_{10}$ e $50 \mathrm{~kg} \mathrm{ha}^{-1}$ no estádio $\mathrm{V}_{15}$. No segundo ano, a adubação de cobertura foi de $270 \mathrm{~kg} \mathrm{ha}^{-1}$ de $\mathrm{N}$, divididos em três parcelas: $90 \mathrm{~kg} \mathrm{ha}^{-1}$ aplicados no estádio $\mathrm{V}_{3}-\mathrm{V}_{4}, 90 \mathrm{~kg} \mathrm{ha}^{-1}$ no estádio $\mathrm{V}_{9}-\mathrm{V}_{10} \mathrm{e}$ $90 \mathrm{~kg} \mathrm{ha}^{-1}$ no estádio $\mathrm{V}_{15}$. Em todas as aplicações, utilizou-se a ureia como fonte de N. A ureia foi aplicada manualmente com o auxílio de copo dosador, com a dose ajustada para cada linha de semeadura.

Cada unidade experimental foi composta por dez linhas de 5,0 m de comprimento, com espaçamento de $0,4 \mathrm{~m}$ entre linhas, o que totalizou área de $20 \mathrm{~m}^{2}$ no primeiro ano, e por oito linhas de 5,0 $\mathrm{m}$ de comprimento, com espaçamento de $0,4 \mathrm{~m}$ entre linhas, o que totalizou área de $16 \mathrm{~m}^{2}$, no segundo ano.

Nos dois anos, o momento para realização das irrigações do milho nos experimentos com irrigação foi determinado pelo monitoramento da umidade do solo com aparelho de "time-domain reflectometry" (TDR). Com a curva de retenção do solo da área experimental, foi obtida a umidade volumétrica do solo referente ao limite hídrico inferior (LHI) que, para o solo em questão, é de $0,18 \mathrm{~m}^{3} \mathrm{~m}^{-3}$. Sempre que a umidade do solo atingia esse valor, medido pelo equipamento TDR, eram realizadas as irrigações. No primeiro ano, utilizouse o sistema de irrigação por aspersão, com vazão de $8,0 \mathrm{~mm}$ por hora. No segundo ano, as irrigações foram realizadas com equipamento autopropelido com barras e bicos de aspersão, com vazão de $16 \mathrm{~mm}$ por hora.

Nos dois anos experimentais, pragas e plantas daninhas foram controladas quimicamente entre $V_{3} e$ $\mathrm{V}_{8}$, sempre que necessário, para não interferir sobre o desenvolvimento das plantas e a produtividade de grãos.

Determinaram-se a produtividade de grãos e os seus componentes (número de espigas por metro quadrado, massa do grão e número de grãos por espiga), a produção de matéria seca da parte aérea e o IAF em $\mathrm{R}_{1}$. A produtividade de grãos foi obtida pela extrapolação da produção obtida na área útil da parcela $\left(9,6 \mathrm{~m}^{2}\right)$ para um hectare, tendo-se corrigido a umidade para $130 \mathrm{~g} \mathrm{~kg}^{-1}$. A área útil colhida era composta pelas seis linhas centrais de cada parcela, tendo-se descartado $0,5 \mathrm{~m}$ das extremidades de cada linha, o que correspondeu a 4,0 m colhidos por linha da área útil. Além disso, foram calculados os balanços hídricos decendiais, 
ao se considerar a capacidade de água disponível no solo de $75 \mathrm{~mm}$, para os dois anos agrícolas, segundo Thornthwaite \& Mather (1957). Os dados utilizados para o cálculo dos balanços hídricos foram coletados na Estação Meteorológica, da Estação Experimental Agronômica, da Universidade Federal do Rio Grande do Sul, localizada no Município de Eldorado do Sul, no mesmo local de condução dos experimentos.

Os dados foram submetidos à análise de variância pelo teste $\mathrm{F}$, a $5 \%$ de probabilidade, com uso do programa SAS (SAS Institute, 2002). No primeiro ano, foi realizada análise conjunta dos dois experimentos com dois níveis de disponibilidade hídrica durante o ciclo da cultura. Já no segundo ano, realizou-se a análise conjunta dos três experimentos, correspondentes aos três níveis de disponibilidade hídrica. Nos dois anos, considerou-se o nível de disponibilidade hídrica como fator aleatório, pois, desta forma, há somente um resíduo (erro), o que aumenta o número de graus de liberdade. Os efeitos simples das médias dos tratamentos e as interações foram comparados pelo teste de Duncan, a 5\% de probabilidade. Também realizou-se a análise de regressão dos dados das variáveis em função de densidade de plantas e híbridos, tendo-se testado os modelos linear e quadrático, a $5 \%$ de probabilidade.

\section{Resultados e Discussão}

Em 2008/2009, nos tratamentos em que o milho foi irrigado entre $V_{15}$ e $R_{2}$, verificou-se a ocorrência de deficiência hídrica no estádio $\mathrm{V}_{3}(8,0 \mathrm{~mm})$; entre os estádios $\mathrm{V}_{11}$ a $\mathrm{V}_{15}(68 \mathrm{~mm})$, antes da aplicação das irrigações durante o período crítico; e no estádio $\mathrm{R}_{4}(8,0 \mathrm{~mm})$, após o término da aplicação das irrigações, o que totalizou deficiência de $84 \mathrm{~mm}$ durante o ciclo (Figura 1 A). Em 2009/2010, houve apenas um período de deficiência hídrica $(24 \mathrm{~mm})$, de aproximadamente dez dias, o que coincidiu com o final do enchimento de grãos (Figura $1 \mathrm{~B}$ ). Em virtude da ocorrência do fenômeno El Niño, o volume de precipitação pluvial do ano agrícola de 2009/2010 foi superior à normal climática da região e se distribuiu uniformemente ao longo do ciclo da cultura.

Nos dois anos agrícolas, o número de espigas por metro quadrado foi afetado pela interação entre densidade de plantas e híbrido. Em 2008/2009, o número de espigas por metro quadrado dos híbridos NB 7502 e 2B707 aumentou de forma quadrática com o incremento da densidade de plantas, enquanto para os híbridos AS 1565 e 30R50 a resposta foi linear (Figura 2 A). Já no segundo ano, esse componente do rendimento aumentou linearmente com o incremento da densidade de plantas nos três híbridos (Figura $2 \mathrm{C}$ ).

$\mathrm{O}$ incremento da densidade de plantas pode causar esterilidade feminina por aumentar a defasagem entre a antese e o espigamento, principalmente sob condições de deficiência hídrica (Tollenaar \& Lee, 2002). No presente trabalho, a esterilidade de plantas possivelmente foi baixa, pois houve aumento no número de espigas por metro quadrado até a densidade de 11 plantas por metro quadrado. Embora não tenha sido avaliada a esterilidade de plantas, no primeiro ano, obteve-se, em média, 10,6 espigas por planta na densidade de 11 plantas por metro quadrado $(3,6 \%$ de esterilidade), e, no segundo ano, obteve-se, em média, 9,8 espigas por planta ( $10 \%$ de esterilidade). Como

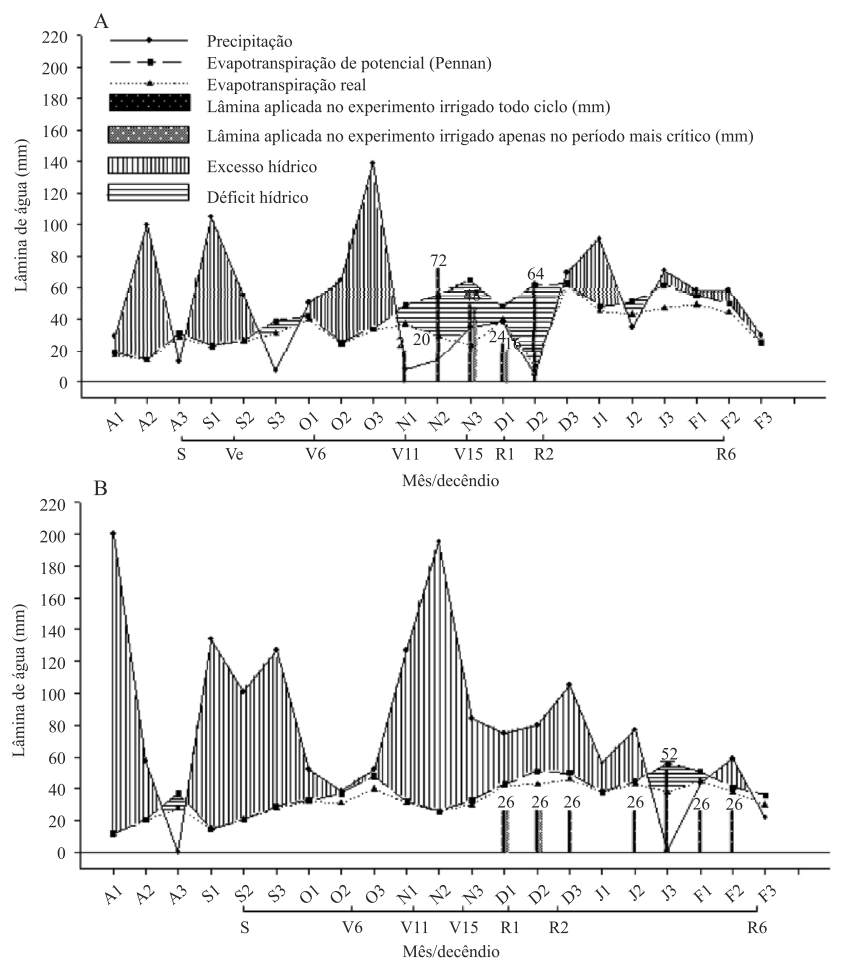

Figura 1. Balanço hídrico referente aos anos agrícolas de 2008/2009 (A) e 2009/2010 (B), tendo-se considerado a capacidade de água disponível no solo, de $75 \mathrm{~mm}$, em Eldorado do Sul, RS. S, semeadura; Ve, emergência; V11, onze folhas completamente expandidas; V15, quinze folhas completamente expandidas; R1, espigamento; R2, grão em forma de bolha; e R6, maturidade fisiológica, segundo escala de Ritchie et al. (1993). 
não ocorreu deficiência hídrica na cultura em função das irrigações no período crítico de formação da inflorescência feminina em 2008/2009 e em razão da adequada precipitação pluvial em 2009/2010, houve sincronia entre a emissão das inflorescências masculina e feminina nos dois anos, o que pode explicar a baixa esterilidade das plantas.

Nos dois anos, o número de grãos por espiga foi afetado pelo efeito simples de nível de disponibilidade hídrica e pela interação entre densidade de plantas e híbrido. Nos tratamentos com irrigação durante todo o ciclo, obteve-se 469 grãos por espiga, valor 15\% maior em comparação aos tratamentos com irrigação apenas no período mais crítico da cultura, no qual obteve-se 406 grãos por espiga. Na interação densidade de plantas e híbrido, o número de grãos por espiga diminuiu de forma linear com o incremento da densidade de plantas, para os híbridos AS 1565 e 30R50. No entanto, esse componente do rendimento não variou nos outros dois híbridos em função da densidade de plantas (Figura 2 B). No segundo ano, nos tratamentos com irrigação durante todo o ciclo, obteve-se 426 grãos por espiga, valor $6 \%$ menor quando comparado aos tratamentos com irrigação apenas no período mais crítico da cultura e sob condições naturais de precipitação pluvial, em que se obteve 455 e 453 grãos por espiga, respectivamente. $\mathrm{Na}$ interação entre densidade de plantas e híbrido, o número de grãos por espiga diminuiu de forma linear com o incremento da densidade de plantas para os híbridos 2A550 e 30R50; para o híbrido Status esse
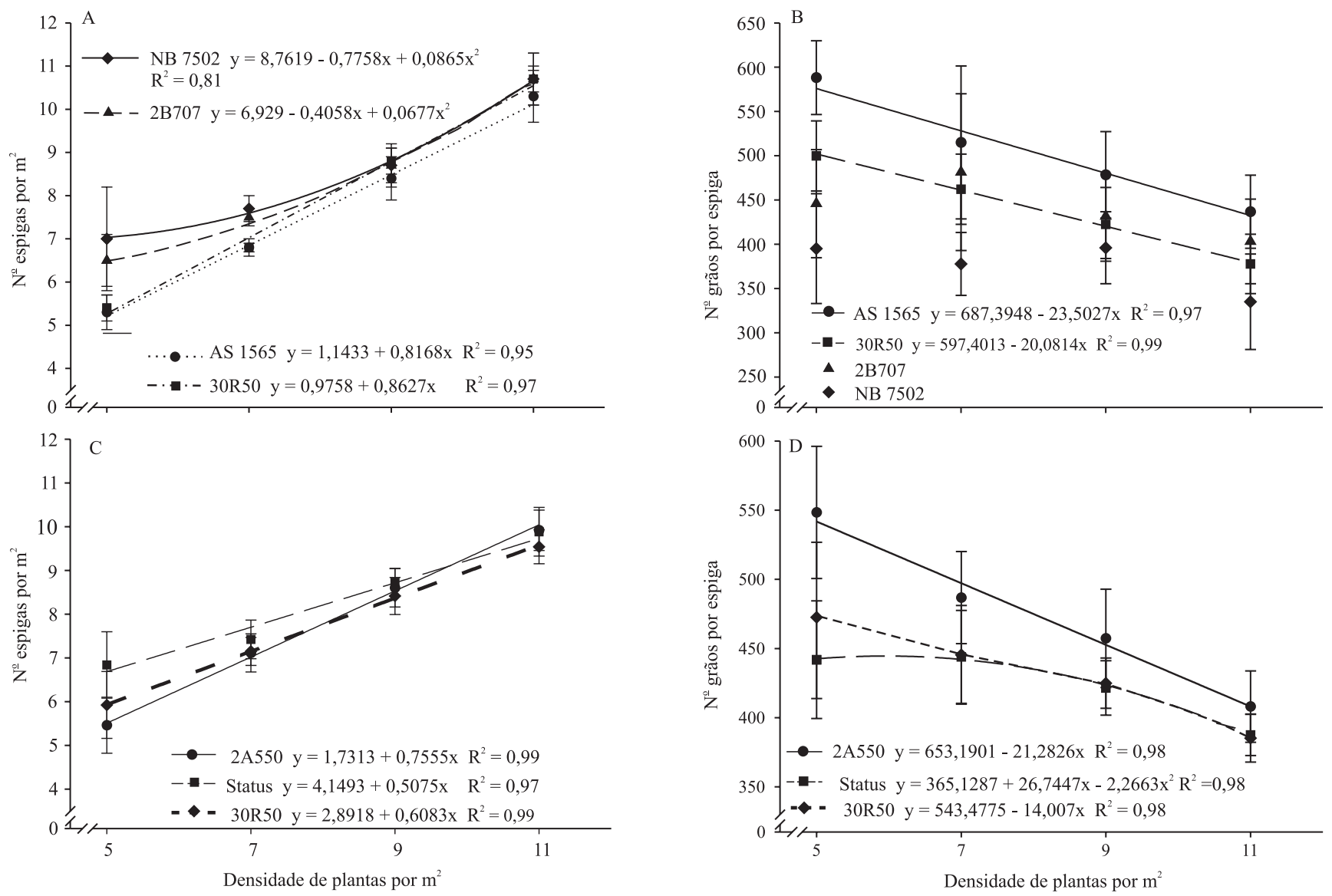

Figura 2. Número de espigas por metro quadrado (A) e número de grãos por espiga (B) em função da densidade de plantas, na média de dois níveis de disponibilidade hídrica no ano agrícola de 2008/2009, e número de espigas por metro quadrado (C) e número de grãos por espiga (D) em função da densidade de plantas, na média de três níveis de disponibilidade hídrica no ano agrícola de 2009/2010, em Eldorado do Sul, RS. 
componente decresceu de forma quadrática (Figura 2 D).

Em 2008/2009, a massa do grão decresceu de forma quadrática com o incremento na densidade de plantas de 5 para 11 plantas por metro quadrado (Figura 3 A). Em 2009/2010, houve redução linear de $7 \%$ na massa do grão com o incremento na densidade de 5 para 11 plantas por metro quadrado. Nos tratamentos conduzidos sob condição natural de precipitação, a massa do grão obtida foi de $387 \mathrm{mg}$ e foi $4 \%$ maior em comparação a dos outros dois níveis de disponibilidade hídrica, em que a massa do grão foi de $372 \mathrm{mg}$.

As reduções no número de grãos por espiga e na massa do grão com o incremento da densidade de plantas podem ser atribuídas ao aumento da competição intraespecífica pelos recursos disponíveis no ambiente. Altas densidades de plantas geralmente reduzem os suprimentos de $\mathrm{N}$, fotoassimilados e água às espigas (Sangoi, 2000). Assim, o decréscimo verificado no número de grãos por espiga com o incremento da densidade pode ser explicado pelo aborto de óvulos recentemente fertilizados no início do enchimento de grãos (Sangoi, 2000) ou pela redução do número de óvulos aptos para a fertilização. Decréscimos nos componentes número de grãos por espiga e massa do grão de milho com o incremento da densidade de plantas também foram observados em outros trabalhos (Marchão et al., 2005; Piana et al., 2008).

Além de ter aumentado a competição intraespecífica pelo incremento da densidade de plantas, a deficiência hídrica ocorrida no primeiro ano, anterior à aplicação das irrigações nos tratamentos que receberam irrigação apenas no período mais crítico, também reduziu a produção de matéria seca das plantas, em comparação aos tratamentos com irrigação sempre que necessário, e, consequentemente, o suprimento de fotoassimilados para os grãos em desenvolvimento. A produção de matéria seca da parte aérea em $R_{1}$ foi $27 \%$ maior nos tratamentos com irrigação sempre que necessário $\left(14,1 \mathrm{Mg} \mathrm{ha}^{-1}\right)$, quando comparados aos com irrigação apenas no período mais crítico da cultura $\left(11,1 \mathrm{Mg} \mathrm{ha}^{-1}\right)$. Isso justifica a redução no número de grãos por espiga nos tratamentos que sofreram deficiência hídrica, em comparação aos com irrigação sempre que necessário durante o ciclo da cultura. Decréscimos no número de grãos por espiga em função da deficiência hídrica também foram observados por Çakir (2004) e Moser et al. (2006).

No primeiro ano, a produtividade de grãos foi afetada pela interação entre nível de disponibilidade hídrica e densidade de plantas. Nos tratamentos com irrigação durante todo o ciclo, a produtividade de grãos aumentou linearmente com o incremento da densidade de plantas de 5 para 11 plantas por metro quadrado, tendo variado de 12,4 a $16,3 \mathrm{Mg} \mathrm{ha}^{-1}$, o que representou aumento de 31\% (Figura 3 B). Para cada incremento de planta por metro quadrado, a produtividade de grãos aumentou em $660 \mathrm{~kg} \mathrm{ha}^{-1}$. Já nos tratamentos com irrigação apenas no período mais crítico da cultura, a resposta da produtividade de grãos ao incremento da densidade de plantas foi quadrática. A densidade de plantas que proporcionou a maior produtividade de grãos foi a de
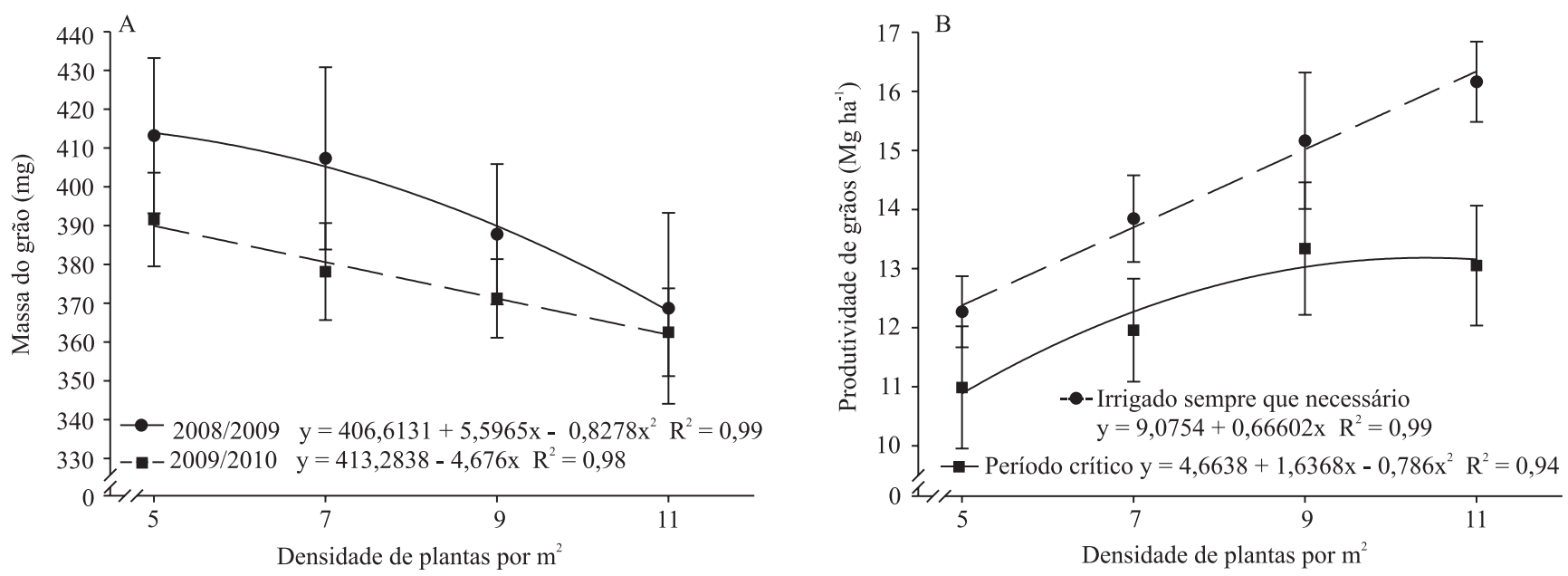

Figura 3. Massa do grão em função da densidade de plantas, na média de níveis de disponibilidade hídrica e híbridos (A), nos anos agrícolas de 2008/2009 e 2009/2010, e produtividade de grãos de milho em função da densidade de plantas e do nível de disponibilidade hídrica, na média de quatro híbridos (B), no ano agrícola de 2008/2009, em Eldorado do Sul, RS

Pesq. agropec. bras., Brasília, v.47, n.4, p.541-549, abr. 2012 
10,4 plantas por metro quadrado. Nesses tratamentos, a produtividade de grãos variou de 10,9 a 13,2 $\mathrm{Mg} \mathrm{ha}^{-1}$, com o incremento da densidade de 5 para 10,4 plantas por metro quadrado, tendo aumentado em $2.300 \mathrm{~kg} \mathrm{ha}^{-1}$, o que representa incremento de $21 \%$ na produtividade de grãos.

O grau de redução da produtividade de grãos em função da deficiência hídrica depende da intensidade do estresse, da sua duração e do estádio em que ele ocorre. No presente trabalho, a redução da produtividade de grãos em função da deficiência hídrica no primeiro ano foi menor em comparação à observada em outros trabalhos, uma vez que, no período mais crítico, o milho foi irrigado. A ocorrência de estresse hídrico no período mais crítico da cultura pode reduzir a produtividade de 50 a 90\%, conforme Pandey et al. (2000) e Çakir (2004). A deficiência hídrica verificada no primeiro ano no milho irrigado apenas no seu período mais crítico reduziu a produção de matéria seca da parte aérea em $R_{1}$, o que pode ter restringido a produção de fotoassimilados. Assim, houve redução no número de grãos por espiga e na produtividade de grãos, e menor resposta ao incremento da densidade de plantas, quando comparado ao milho irrigado sempre que necessário durante o ciclo. No entanto, a máxima produtividade de grãos no milho irrigado apenas no período mais crítico da cultura superou a $13 \mathrm{Mg} \mathrm{ha}^{-1}$ e foi obtido com alta densidade de plantas (10,4 plantas por metro quadrado), mesmo sob condições de deficiência hídrica de $84 \mathrm{~mm}$ durante o ciclo, o que representa $15 \%$ da exigência hídrica total da cultura. Como não houve deficiência hídrica entre $V_{15} \mathrm{e}$ $\mathrm{R}_{2}$, em virtude das irrigações realizadas, a esterilidade de plantas foi baixa, o que proporcionou alta resposta de produtividade de grãos ao incremento da densidade nos dois níveis de disponibilidade hídrica avaliados.

Em 2009/2010, foi significativa a interação tripla entre nível de disponibilidade hídrica, densidade de plantas e híbrido. Na comparação entre níveis de disponibilidade hídrica, observou-se que, para o híbrido 2A550, a resposta da produtividade de grãos ao incremento da densidade de plantas foi quadrática apenas nos tratamentos com irrigação durante todo o ciclo, enquanto nos outros dois níveis de irrigação o aumento foi linear (Figura 4). Para o híbrido Status, a produtividade de grãos aumentou de forma linear com o incremento da densidade de plantas; porém, para o híbrido 30R50, a resposta foi quadrática, independentemente do nível de disponibilidade hídrica. Nesse ano, as máximas produtividade de grãos também foram obtidas com densidades de plantas acima de nove plantas por metro quadrado, para os
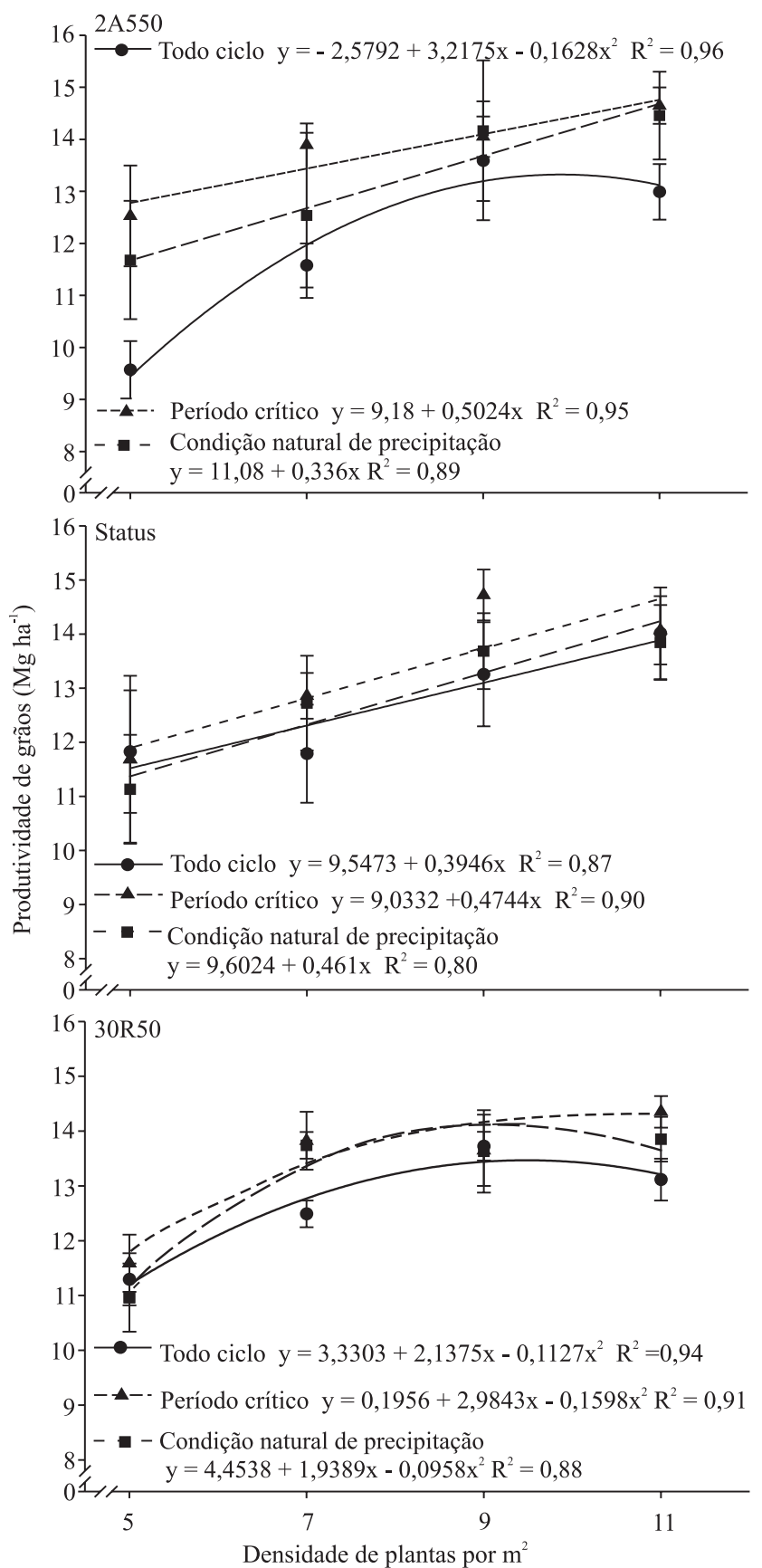

Figura 4. Produtividade de grãos de três híbridos de milho em função da densidade de plantas nos tratamentos com irrigação durante todo o ciclo, com irrigação apenas no período mais crítico da cultura (V15 a R2) e sob condições naturais de precipitação pluvial no ano agrícola de 2009/2010, em Eldorado do Sul, RS. 
três híbridos testados e independentemente do nível de disponibilidade hídrica.

Diferentemente do esperado para a maioria dos anos, observou-se, no segundo ano, menor produtividade de grãosnos tratamentos em que o milho foi irrigado durante todo o ciclo de desenvolvimento, em comparação aos outros dois níveis de disponibilidade hídrica. É possível que tenha ocorrido perda de $\mathrm{N}$ por lixiviação em razão do excesso de água disponível durante quase todo o ciclo. Isso porque, embora tenha ocorrido elevado volume de precipitação pluvial durante praticamente todo o ciclo da cultura, em função da ocorrência do fenômeno El Niño, várias vezes, durante o ciclo, a umidade do solo medida estava próxima ao limite hídrico inferior para a cultura $\left(0,18 \mathrm{~m}^{3} \mathrm{~m}^{-3}\right)$. Nesses momentos, eram realizadas as irrigações nos dois tratamentos com irrigação complementar. No entanto, logo após a realização das irrigações, ocorriam novas precipitações. Com isso, uma vez que a alta quantidade de precipitação ocorrida $(1.687 \mathrm{~mm})$ ultrapassou em muito as exigências hídricas da cultura $(570 \mathrm{~mm})$ (Matzenauer et al., 2002), foram aplicados mais $208 \mathrm{~mm}$ nos tratamentos com irrigação durante todo o ciclo e mais $52 \mathrm{~mm}$ nos tratamentos com irrigação apenas no período mais crítico da cultura.

A possível perda de $\mathrm{N}$ do solo também pode ter contribuído para a redução verificada na massa do grão nos dois tratamentos que receberam irrigação complementar, quando comparado aos conduzidos sob condições naturais de precipitação pluvial, já que o $\mathrm{N}$ é o nutriente que mais frequentemente limita a produtividade de grãos de milho.

No primeiro ano, nos tratamentos com irrigação durante todo o ciclo, o IAF em $\mathrm{R}_{1}$ foi $9 \%$ maior em comparação ao dos com irrigação apenas no período mais crítico da cultura, ou seja, de 6,0 e 5,5, respectivamente. Além disso, a resposta do IAF ao incremento da densidade de plantas foi linear, tendo aumentado $94 \%$ com o incremento de 5 para 11 plantas por metro quadrado. No segundo ano, o IAF em $\mathrm{R}_{1}$ também aumentou de forma linear em $83 \%$, com o incremento da densidade de plantas de 5 para 11 plantas por metro quadrado. Na semeadura antecipada para o final de inverno, o milho se desenvolve sob menores temperaturas do ar e do solo e menor disponibilidade de radiação solar. Essas características climáticas restringem o crescimento vegetativo da cultura, o que propicia a formação de plantas baixas, com área foliar reduzida (Sangoi et al., 2010b). Portanto, o incremento da densidade de plantas acima de nove plantas por metro quadrado, superiores às atualmente recomendadas para potencializar o rendimento sob condições ótimas de manejo, que se situam entre sete e oito plantas por metro quadrado (Indicações técnicas para o cultivo de milho e de sorgo no Rio Grande do Sul - safras 2009/2010 e 2010/2011, 2009), é uma estratégia eficiente para compensar o menor desenvolvimento das plantas nas semeaduras antecipadas para o final do inverno, o que aumenta a produtividade de grãos mesmo em condições de deficiência hídrica, desde que esta não ocorra entre os estádios $\mathrm{V}_{15}$ e $\mathrm{R}_{2}$.

\section{Conclusão}

A utilização de híbridos de milho modernos e densidades de plantas superiores a nove plantas por metro quadrado é uma estratégia eficiente para otimizar a produtividade de grãos de milho nas semeaduras antecipadas para o final de inverno das regiões mais quentes do Sul do Brasil, tanto em ambientes irrigados quanto em ambientes de sequeiro, desde que não haja deficiência hídrica entre os estádios $\mathrm{V}_{15}$ e $\mathrm{R}_{2}$.

\section{Referências}

BORRAS, L.; WESTGATE, M.E.; ASTINI, J.P.; ECHARTE, L. Coupling time to silking with plant growth rate in maize. Field Crops Research, v.102, p.73-85, 2007.

ÇAKIR, R. Effect of water stress at different development stages on vegetative and reproductive growth of corn. Field Crops Research, v.89, p.1-16, 2004.

CAMPOS, H.; COOPER, M.; HABBEN, J.E.; EDMEADES, G.O.; SCHUSSLER, J.R. Improving drought tolerance in maize: a view from industry. Field Crops Research, v.90, p.19-34, 2004.

DUVICK, D.N. What is yield? In: EDMEADES, G.O.; BANZIGER, M.; MICKELSON, H.R.; PENA-VALDIVIA, C.B. (Ed.). Developing drought and low N-tolerant maize. El Batan: CIMMYT, 1997. p.332-335.

INDICAÇÕES técnicas para o cultivo de milho e de sorgo no Rio Grande do Sul - safras 2009/2010 e 2010/2011. Passo Fundo: Embrapa Trigo, 2009. 179p.

MARCHÃO, R.L.; BRASIL, E.M.; DUARTE, J.B.; GUIMARÃES, C.M.; GOMES, J.A. Densidade de plantas e características agronômicas de híbridos de milho sob espaçamento reduzido entre linhas. Pesquisa Agropecuária Tropical, v.35, p.93-101, 2005.

MATZENAUER, R.; BERGAMASCHI, H.; BERLATO, M.A.; MALUF, J.R.T.; BARNI, N.A.; BUENO, A.C.; DIDONÉ, I.A.; ANJOS, C.S. dos; MACHADO, F.A.; SAMPAIO, M. dos R. Consumo de água e disponibilidade hídrica para milho e 
soja no Rio Grande do Sul. Porto Alegre: Fepagro, 2002. 105p. (Fepagro. Boletim, 10).

MOSER, S.B.; FEIL, B.; JAMPATONG, S.; STAMP, P. Effects of pre-anthesis drought, nitrogen fertilizer rate, and variety on grain yield, yield components, and harvest index of tropical maize. Agricultural Water Management, v.81, p.41-58, 2006.

PANDEY, R.K.; MARANVILLE, J.W.; ADMOU, A. Deficit irrigation and nitrogen effects on maize in a Sahelian environment I. Grain yield and yield components. Agricultural Water Management, v.46, p.1-13, 2000.

PEIXOTO, C.; SILVA, P.R.F. da; REZER, F.; CARMONA, R.C. Produtividade de híbridos de milho em função da densidade de plantas, em dois níveis de manejo da água e da adubação. Pesquisa Agropecuária Gaúcha, v.3, p.63-71, 1997.

PENARIOL, F.G.; FORNASIERI FILHO, D.; COICEV, L.; BORDIN, L.; FARINELLI, R. Comportamento de cultivares de milho semeadas em diferentes espaçamentos entrelinhas e densidades populacionais, na safrinha. Revista Brasileira de Milho e Sorgo, v.2, p.52-60, 2003.

PIANA, A.T.; SILVA, P.R.F. da; BREDEMEIER, C.; SANGOI, L.; VIEIRA, V.M.; SERPA, M. da S.; JANDREY, D.B. Densidade de plantas de milho em semeadura precoce no Rio Grande do Sul. Ciência Rural, v.38, p.2608-2612, 2008.

RITCHIE, S.W.; HANWAY, J.J.; BENSON, G.O. How a corn plant develops? Ames: Iowa State University, 1993. (Special report, 48).
SANGOI, L. Understanding plant density effects on maize growth and development: an important issue to maximize grain yield. Ciência Rural, v.31, p.159-168, 2000.

SANGOI, L.; SILVA, P.R.F. da; ARGENTA, G. Estratégias de manejo do arranjo de plantas para aumentar o rendimento de grãos de milho. Lages: Graphel, 2010a. 64p.

SANGOI, L.; SILVA, P.R.F. da; ARGENTA, G.; RAMBO, L. Ecofisiologia da cultura do milho para altos rendimentos. Lages: Graphel, 2010b. 87p.

SAS INSTITUTE. SAS/STAT: user's guide. Version 8.1.Cary: SAS Institute, 2002. 890p.

STRECK, E.V.; KÄMPF, N.; DALMOLIN, R.S.D.; KLAMT, E.; NASCIMENTO, P.C. do; SCHNEIDER, P.; GIASSON, E.; PINTO, L.F.S. Solos do Rio Grande do Sul. Porto Alegre: UFRGS, 2008. 222p.

THORNTHWAITE, C.W.; MATHER, J.R. Instructions and tables for computing potential evapotranspiration and the water balance. Centerton: Drexel Institute of Technology, 1957. 257p. (Publications in climatology, 10).

TOLLENAAR, M.; LEE, E.A. Yield potential, yield stability and stress tolerance in maize. Field Crops Research, v.75, p.161-169, 2002.

VON PINHO, R.G.; GROSS, M.R.; STEOLA, A.G.; MENDES, M.C. Adubação nitrogenada, densidade e espaçamento de híbridos de milho em sistema plantio direto na região sudeste do Tocantins. Bragantia, v.67, p.733-739, 2008.

Recebido em 19 de abril de 2011 e aprovado em 5 de março de 2012 